\title{
Prolegomena to Virtue-Theoretic Studies in the Philosophy of Mathematics
}

\author{
james.v.martin@wmich.edu
}

\begin{abstract}
The paper begins by arguing that additional theorizing about mathematical practice is needed in order to ground appeals to truly useful notions of the virtues in mathematics. It then aims to contribute to this theorizing, first, by characterizing mathematical practice as being epistemic and "objectual" in the sense of Knorr Cetina (2001). Then, it elaborates a MacIntyrean framework for extracting conceptions of the virtues related to mathematical practice so understood. Finally, it makes the case that Wittgenstein's methodology for approaching mathematics and its practice provides the appropriate perspective from which to undertake the actual investigation of mathematical practice within this MacIntyrean framework for the virtues. During each stage of thinking through mathematical practice by these means, places where new virtue-theoretic questions are opened up for investigation are noted and briefly explored.
\end{abstract}

Keywords: virtue; mathematical practice; MacIntyre; Wittgenstein

\section{Introduction}

That the concept of a virtue requires some prior account of the "features of social and moral life in terms of which it has to be defined and explained" is one of 
the key ideas of Alasdair MacIntyre's After Virtue. ${ }^{1}$ It's natural for anyone taking a "practice-first" approach to the philosophy of mathematics to share this basic sentiment and, therefore, suggest that a more sophisticated view of the structural features of mathematical practice in terms which virtue-theoretic concepts can be defined and explained is necessary prior to the effective application of such concepts to mathematics and its practice. In what follows, I'll aim to facilitate this kind of application by improving upon existing accounts of practice and virtue employed in the field, while also taking note of places where this improved account makes room for interesting virtue-theoretic studies to be undertaken. ${ }^{2}$

In more detail, the plan for the paper is as follows. In Section 2, I'll argue that there is still room for expanding on the notions of mathematical practice most commonly relied upon in the literature. Next, Section 3 will begin to fill in this room by characterizing mathematical practice generally as being an epistemic, "objectual" practice in the sense of Knorr Cetina (2001). MacIntyre's three-part analysis of the concept of a virtue relative to a practice will then be used to lay out a broad framework for exploring mathematical practice and extracting conceptions of the virtues in connection with it in Section 4. It's primarily here that we'll see an opening of new space for thinking about roles for the virtues-both intellectual and practical-in the world of mathematics. Section 5 will go on to outline a "realistic" methodology that I'll argue should be employed when investigating the various aspects of mathematical practice delineated thus far. ${ }^{3}$ The usefulness of a

\footnotetext{
${ }^{1}$ (MacIntyre 1981: 186)

${ }^{2}$ Note that my claim isn't that pursuing, say, a virtue-based epistemology for mathematical knowledge as in Tanswell (2016) needs to wait until we have a perfectly adequate understanding of mathematical practice. However, the more realistic and detailed our picture of the kind of practical and intellectual virtues a mathematical knower can be expected to exhibit is, the more likely a view of this sort is to be compelling. My contention is simply that a clearer view of mathematical practice can help provide this more realistic view of the virtues surrounding the practice.

${ }^{3}$ This type of realistic approach—characterized by "the realistic spirit," which looks to pay close attention to our ordinary, everyday practices - is largely inspired by the work of Ludwig Wittgenstein (in Wittgenstein (1953/2009), for example), who in many ways is rightly seen as a philoso-
} 
realistic methodology of this sort will be briefly illustrated in this section as well in relation to the question of the (dis)unity of mathematicians' opinions about the virtues of certain styles of proof. Finally, I'll close in Section 6 by discussing some of the questions this general approach to the philosophy of mathematical practice ought to lead us to pose and by noting some prospects for future virtue-theoretic work in this direction.

\section{On the Need for and Problems with Theorizing Practice}

Juliet Floyd has recently called for more efforts aimed at theorizing mathematical practice in practice-oriented philosophy of mathematics, suggesting that "not enough has been done to pick apart the force, the character, and the scope of what an appeal to, or characterization of, mathematical practice should and can be."4 That she's right to make this request can be seen by looking at some of the characterizations of practice that philosophers of mathematics currently work with: e.g., "By a "practice" in general I mean a recognizable type of activity that is doneand can be taught and learned - by human agents," captured by a tuple consisting of 'agents' and 'mathematics', which can be written as $\langle A, M\rangle . "$ 6,7 These definitions of practice (and others like them) seem to be unexceptionable as far as they go, but they also don't seem to go very far. Even when

pher of mathematical practice. Cf., e.g., Shanker (1987), Mühlhölzer (2010), Floyd (2012), and Mühlhölzer (2014). See also Diamond (1996), (Laugier 2013: xi-xii), and (Methven 2015: Ch. 1) on "ordinary realism" and the realistic spirit.

${ }^{4}$ (Floyd 2015: 17)

${ }^{5}$ (Ferreirós 2016: 28, emphasis in the original)

${ }^{6}$ (Carter 2019: 24)

${ }^{7}$ It's not my intention to single out any particular definition of practice as being especially bad of course. On its own, the fact that there are so many attempts to say what a practice is supposed to be in the philosophy of mathematics already suggests that there's still work to be done. 
Jessica Carter draws on some of the ideas in Soler (2012) to help particularize the general "tuple"-definition of practice she begins with, we're only told that we should further see mathematical practice (roughly) as a cluster of ongoing, human processes that make up the ordinary (i.e., day-to-day and non-idealized) activities of mathematicians. ${ }^{8}$

Philip Kitcher's earlier analysis of mathematical practice as consisting of "a language, a set of accepted statements, a set of accepted reasonings, a set of questions selected as important, and a set of metamathematical views"9 and its expansion in Van Bendegem and Van Kerkhove (2004) ${ }^{10}$ looks like it offers more tools and concepts to work with, but the definition still appears rather abstract and static when compared to characterizations of practice routinely put to use in the social, moral, or political sciences. ${ }^{11}$ Consider, for instance, Joseph Dunne's restatement of MacIntyre's well-known account of practice from After Virtue.

[A practice] is a coherent, complex set of activities that has evolved cooperatively and cumulatively over time, that is alive in the community who are its practitioners, and that remains alive only so long as they remain committed to sustaining - and creatively developing and extending - its internal goods and its proper standards of excellence (this commitment constituting them as a community) (Dunne 2005: 367).

I expect that this way of conceptualizing a practice immediately sounds like it provides a richer core idea around which to connect the details of something like Kitcher's or Van Bendegem and Van Kerkhove's tuples than the previously-mentioned

\footnotetext{
${ }^{8}$ See (Carter 2019: 25-26).

${ }^{9}$ (Kitcher 1984: 163-165)

10“Math[imatical]Pract[ice] $=\langle M, P, F, P M, C, A M, P S, \ldots\rangle$ (as a reminder: $M=$ community of mathematicians, $P=$ research program, $F=$ formal language, $P M=$ proof methods, $C=$ concepts, $A M=$ argumentative methods, $P S=$ proof strategies)" (Van Bendegem and Van Kerkhove 2004: 534).

${ }^{11}$ See, e.g., (Rouse 2003: Ch. 5) for discussion.
} 
starting points, but I take it to be clear that at least prima facie reason has been given to think that philosophers of mathematics need to spend some time arguing for and about the very conception of mathematical practice that gives practice-oriented philosophy of mathematics its distinctive character. ${ }^{12}$ This is, again, especially true for virtue-based investigations in the philosophy of mathematics if an account of the practice must be in place before we can hope for effective thinking about mathematical virtues to get underway.

That this theorizing and argumentation hasn't occurred to the extent that it should have may be traceable to the relative youth of the practice-first approach or to the distance between the interests of many mathematically-minded philosophers and, say, sociology. But the lack can also potentially be explained by some of the aims of the practice-first approach itself. Philosophers taking this view of the subject have often done so with a fear of philosophical presuppositions infecting their observations of mathematics and its practices. ${ }^{13}$ By looking at mathematical practice with eyes unobstructed by prior theorizing, they've hoped to be able to observe the world of mathematics and of mathematicians without the worry of unconsciously cherry-picking cases and examples to arrive at antecedently-determined conclusions. There are echoes here, however, of the "dilemma of case studies" faced by other philosophers of science years ago: if we approach mathematical practice looking to confirm our preconceived notions of it, it's not clear that the data we'll appeal to hasn't been manipulated to fit the notions; if we start with a simple case study, on the other hand, it's not clear how to proceed from there-it's unreasonable to generalize from a case or two or three. ${ }^{14}$ Obviously, there's something correct about this sort of concern and the attempts to assuage it that come out of the "anti-theory" line of thought. But since the dilemma of case studies has rea-

\footnotetext{
${ }^{12} \mathrm{I}$ am, therefore, basically in agreement with Colin Rittberg that " $[\mathrm{t}] \mathrm{h}$. philosophy of mathematics needs a body of knowledge which critically assesses our philosophical methods (to engage with mathematical practices and otherwise)" (Rittberg 2019: 14).

${ }^{13}$ See Cellucci (2013) for a discussion of "top-down" and "bottom-up" philosophy of mathematics.

${ }^{14}$ This version of the dilemma is taken almost verbatim from (Pitt 2001: 373).
} 
sonably been thought to have been overcome in the rest of philosophy of science, we shouldn't especially take ourselves to be caught on its horns in the philosophy of mathematics. As Richard Burian writes, "[M]ethodologically and epistemologically useful case studies need not be philosophically innocent and need not proceed to grand conclusions by induction from absurdly small samples." ${ }^{15}$ We should, this suggests, forge ahead with theorizing about what mathematical practice is and can be, and about our methodological principles in general, without fearing too much the pollution of our vision by theory.

\section{Mathematical Practice as an Epistemic, Objectual Practice}

Let's return then to the theorizing and conceptualization of practice and take as a starting point the much-quoted characterization found in After Virtue.

By a 'practice' I am going to mean any coherent and complex form of socially established cooperative human activity through which goods internal to that form of activity are realized in the course of trying to achieve those standards of excellence which are appropriate to, and partially definitive of, that form of activity, with the result that human powers to achieve excellence, and human conceptions of the ends and goods involved, are systematically extended (MacIntyre 1981: 187).

This way of conceiving of a practice adds to standard accounts by making efforts to extend and develop certain forms of goods and excellences pursued within the practice partially constitutive of the cooperative activity itself. That is, a practice in MacIntyre's sense is still seen as being a "a temporally unfolding and spatially dispersed nexus of doings and sayings," where the doings and sayings form a nexus

${ }^{15}$ (Burian 2001: 388) 
because they are connected in various ways: e.g., through shared practical understandings or interpretations; through explicit rules or principles; and through embracing ends or beliefs. ${ }^{16}$ But these temporal unfoldings are specialized to those for which goods "internal" to the activity can be achieved and enriched as well as to those that expand on some version of human flourishing through the achievement of excellence(s). Whether or not every practice is really a practice in MacIntyre's sense can be set aside for now, since I take it that the main object of concern here, mathematical practice, does have the features of a practice in this, perhaps special, sense.

In order to fully understand MacIntyre's conception of a practice, we need to have the idea of what an "internal good" is supposed to be in hand first. MacIntyre himself illustrates the distinction between internal and "external" goods by considering a parent trying to teach her daughter to play chess. As motivation, the parent offers the child a piece of candy every time she wins a game. The child can manage to get candy in many other ways (let's suppose), but she can only get the goods of a certain kind of competition and intellectual excellence through learning how to identify with them as she engages in the practice of chess. She can only recognize these goods as goods through her participation in and shaping by the practice. MacIntyre calls goods achievable and recognizable in this way "internal," while goods like candy, fame, and fortune are said to be "external." 17,18 We'll see in Section 4, that virtues for MacIntyre are initially characterized as qualities that allow

\footnotetext{
${ }^{16}$ (Schatzki 1996: 89)

${ }^{17}$ Internal goods are also characterized by being less likely to be limited in supply and less likely to be limited to being good just for me than external goods. So, if I get a raise, that means there's less money in the company available for you, and you're not particularly benefited by my improved financial standing. But if I invent a new technique in painting - a technique that can perhaps be seen to be the good that it is only by those within the practice- the practice is now no less likely to develop other new techniques and you can also benefit from my advance nearly as much as I can. ${ }^{18}$ Using this terminology, we can say that (Bourdieu 1977: 183) suggests, contra MacIntyre, that people take part in practices aiming for the external good of "symbolic capital." $C f$. (Hicks and Stapleford 2016: 463).
} 
a person to better achieve the goods that can be found internal to practices, but for now I'll turn to the work of Karin Knorr Cetina to help further clarify the nature of mathematical practice as one MacIntyrean practice among many.

Some human practices pursue excellence in various forms of behaving or thinking; e.g., as in the practice of farming or of chess. These practices can generate large bodies of knowledge, but may not be best seen as essentially aiming at the generation of such knowledge. (Instead, the aims may be to produce healthful food responsibly or to win a position intelligently.) Mathematical practice, howeverwhatever else it may be-does seem to be properly conceived of as "knowledgecentered" or, in other words, as an "epistemic" practice. Among their other activities, mathematicians must generate and manage practices for acquiring knowledge about their areas of specialization as well as continually formulate, confront, and solve nonroutine problems, which further generate bodies of knowledge and means of understanding. These features of mathematical practice make it a creative and constructive practice of the sort Knorr Cetina characterizes in her work on "objectual practices," where an objectual practice is one that seeks to produce knowledge and understanding of "epistemic objects," a type of object that will be characterized with the help of Heidegger presently. ${ }^{19}$ Knorr Cetina is correct when she points out that objectual practices require the use of concepts different from the ones that have been developed for thinking about more practical practices like baseball or cooking. These objectual practices minimally present us with unique additional questions, "For example, how can we theorize practice in a way that allows for the engrossment and excitement — the emotional basis_-of research work? What characterization of practice might make the notion more dynamic and include within it the potential for change?"20

\footnotetext{
${ }^{19}$ See, e.g., Knorr Cetina (2001) and (Knorr-Cetina 1981: 152). Knorr Cetina's work has been influential in sociology of science studies, but unfortunately seems not to have made its way into the literature of philosophy of mathematics yet.

${ }^{20}$ (Knorr Cetina 2001: 184)
} 
In order to get a sense of what Knorr Cetina means by an "epistemic object"the type of object investigated by an objectual practice-it will be useful to employ (as she does herself) Heidegger's notion of an object being "ready-to-hand" (Zuhanden). The idea of readiness-to-hand has been thought to capture well the way in which a tool in the hands of an expert user can function effortlessly and even seem to vanish from the user's awareness (as the practitioner herself may vanish from her own purview when engrossed in a project). ${ }^{21}$ Although there are certainly times within ordinary mathematical practice when objects or techniques appear as being ready-to-be-used without further thought (e.g., once a space has been mapped to an algebraic object, the tools of group theory may seem to almost apply themselves), it's also just as certain that objects of study may present themselves as unwieldy or as obstacles to be overcome for which one can find no tool to attack properly (e.g., most of the questions about the rationality or irrationality of numbers like $\pi e, \pi^{\pi}$, and so on are unsettled and often thought to be beyond the reach of current methods). In other words, in mathematical research, the researcher may often find that her objects of investigation are unknown or incomplete in various ways or that her tools appear to be useless and very much not working smoothly and invisibly along with her intentions; i.e., they suddenly appear to be anything but ready-to-hand. ${ }^{22}$ It's the stubborn, unknown, and incomplete nature of an object under investigation like this that fuels the dynamics of research on Knorr Cetina's account. These objects of research are seen to be "characteristically open, question-generating and complex. They are processes and projections rather than definitive things. Observation and inquiry reveals them by increasing rather than reducing their complexity." ${ }^{23}$ Objects of this sort are what Knorr Cetina means by epistemic objects, and they are the objects towards which objectual practices direct themselves. ${ }^{24}$

\footnotetext{
${ }^{21}$ (Heidegger 1927/1962: par. 15:68-70)

${ }^{22} C f$. (Knorr Cetina 2001: 188).

${ }^{23}$ (Knorr Cetina 2001: 190)

${ }^{24}$ Occasional difficulties in applying tools or understanding how to make use of equipment are sig-
} 
Knorr Cetina's account of objectual practices isn't aimed at capturing research in mathematics specifically, but it clearly finds natural application there. For example, Radford (2008) and Font et al. (2013) have seen mathematical objects in terms of the patterns of activity they allow for in practice, and Emily Grosholz has carried out a book-length study on the roles this type of openness and incompleteness can play in providing for the "productive ambiguity" involved in the "investigation and creation" of mathematical objects. ${ }^{25}$ This suggests that mathematical objects can be seen as having the features of epistemic objects in Knorr Cetina's sense. While her own view seems to be that we should think of epistemic objects themselves, not just our knowledge of them, as being incomplete and part of an "unfolding ontology," 26 for present purposes not much seems to hang on whether we accept this incompleteness as part of the object itself or as stemming from our incomplete knowledge of the object. If that's correct, the philosopher of mathematical practice can accept the phenomenological insights offered by Knorr Cetina's account without violating, e.g., the stricture in (Larvor 2001: 218), which claims that we shouldn't be taking a stand on ontological issues qua philosophers of mathematical practice.

The insights gleaned from Knorr Cetina's work about objectual practices suggest that the import of the incompleteness of (our understanding of) the objects of research is primarily that these lacks recommend further research questions and, further, create structures of desires and wantings that can be seen to motivate prac-

nificant for Heidegger's overall story in Being and Time as well, but for different reasons. These sorts of problems-a piece of equipment's conspicuousness (Auffälligkeit), obtrusiveness (Aufdringlichkeit), or obstinacy (Aufsässigkeit)—can reveal the otherwise hidden "worldliness of the world" to us, but they aren't themselves motivators of further investigations into particular objects of concern. See (Heidegger 1927/1962: par. 16).

${ }^{25}$ (Grosholz 2007: 47)

${ }^{26}$ See (Knorr Cetina 2001: 185). In fact, she goes so far as to use the Sartrean language of the epistemic object's being what it isn't and not being what it is, like the "for-itself" (Sartre 1943/1993: $1 \times v)$, at times. 
titioners to conduct the research necessary to at least temporarily satisfy them. ${ }^{27}$ In the specific case of mathematical research, these desires and wantings can lead-in addition to the ordinary pursuit of understanding - to the sorts of conjectures that push research forward as discussed in, e.g., Mazur (1997). They can also be generated by presenting and puzzling over "mathematical coincidences" that seem to defy explanation, as pursued in Davis and Hersh (1981), Baker (2009), and Lange (2010). A mathematical coincidence presents us with, among other things, an apparent lack of knowledge, and so can naturally be seen as generating an impetus to increased attention and research.

Seeing mathematics as an epistemic, objectual practice in the sense of Knorr Cetina also helps to reveal numerous places where the virtues can come to play an important role in understanding and perhaps even influencing mathematical practice. Given that the practices of production and maintenance of knowledge seem to have changed significantly and can be expected to continue to change as our base of mathematical knowledge grows, more thought will have to be given to virtuous forms of these practices. For example, in the past two years (2018-2019), $63 \%$ of the papers published in Annals of Mathematics have more than one author. From 1990-1991, the number was 39\%; 23\% from 1962-1963; and 13\% from 1934-1935. Clearly, it appears as if the generation of mathematical knowledge is becoming more and more cooperative. It's perhaps even possible to view mathematical researchers as being more and more enmeshed in the machinery of knowledge construction within their particular fields, where the production of knowledge is governed more by collective projects and goals than by single actors pursuing individual knowledge or understanding. ${ }^{28}$ Proofs, such as the proof of the classification of finite simple groups, are also becoming of almost unmanageable length, again requiring cooperation in both their production and verification. How can these facts of mathematical practice be accommodated and managed in the best

\footnotetext{
${ }^{27}$ (Knorr Cetina 2001: 194)

${ }^{28}$ See (Knorr Cetina 1999: 11) for an account of science in general along these lines.
} 
way? Focusing on the virtues that foster the practice of open and shared cooperative research in the course of mathematical training might be an important choice for the discipline to commit to. Questions about the appropriate maintenance of and availability of access to mathematical knowledge bases can also be usefully raised here.

These kinds of questions aren't strictly for philosophers to answer of course. When a field faces problems and questions like the ones raised by the changing facts of research and knowledge production in mathematics, it's generally to be expected that the field itself will be forced to work out a solution (or solutions) in order to progress. ${ }^{29}$ However, significant work attempting to address these and similar questions in fields like engineering and medical ethics has already been done, and this work can find application in mathematics well. Students entering engineering or medical fields are generally required to have some kind of basic training in ethics, ${ }^{30}$ perhaps something similar is becoming reasonable in the case of mathematical training. Discussion of professional virtues is also becoming more important for mathematicians to consider given the importance of the roles of mathematicians in the world of finance, security, and the military. The characterization of mathematical research objects as generating desires and wants that motivate exploration also naturally (and a bit more fancifully) raises questions about virtuous means for satisfying those desires. Alfréd Rényi is supposed to have said that a mathematician is a device for turning coffee into theorems. We might want to ask ourselves whether this presents us with a picture of a flourishing

\footnotetext{
${ }^{29}$ E.g., one of the motivations for active research into computer-verified proofs, say, using Coq, Mizar, or Isabelle, is both to check long, complicated proofs and to provide an easily accessible store of mathematical results.

${ }^{30}$ Thinking in terms of the virtues seems to be becoming more prevalent in these fields in recent years as well. For example, the most recent edition of Engineering Ethics: Concepts and Cases Harris et al. (2019), one of the most widely-used textbooks on the subject, has now added sections incorporating virtue ethics into the tools it hopes to provide its readers.
} 
human life.$^{31}$ If so, in what sense? If not, what might be missing? How can an answer to this kind of question even be approached? In the next section, I'll outline a framework for thinking about the virtues in relation to mathematical practice that aims to provide some tools for settling questions of this sort.

\section{A MacIntyrean Framework for Mathematical Virtues}

Having finished presenting a very general characterization of some of the objects and goals of mathematical practice, I'll proceed to offer a framework within which thinking about the virtues in connection with the pursuit of these goals can be fruitfully undertaken. The framework takes its main inspiration from the ideas of MacIntyre.

\subsection{Recapitulation of MacIntyre's Account in Ethics}

MacIntyre offers an account of the virtues after having taken three preliminary steps. First, he offers a characterization of practices; then he suggests the need for a conception of the narrative structure of a single human life and its goods to supplement and structure this initial understanding of practices; finally, he considers the role of a "moral tradition" in providing the context within which to make sense of both practices and the ends of a human life in general. For a trainable characteristic to be a virtue, it must be a trait that helps one achieve the internal goods of practices as well as sustain a general aim for the goods achievable over the course of a human life within a moral tradition that it also helps to nurture and advance.

MacIntyre's account of a practice has already been discussed, and in the course of that discussion, I noted that the first test a character trait must pass in order to be counted as a virtue is whether or not it contributes to the achievement of goods

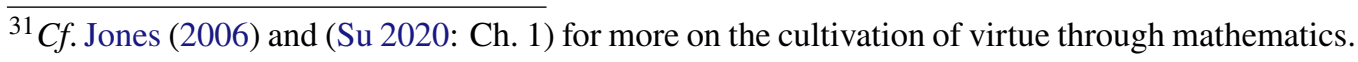


internal to these practices. If it does, it is at least potentially a virtue. ${ }^{32}$ Since there are practices and virtues that compete with one another however, e.g., perhaps ballet and bodybuilding, MacIntyre further suggests that we need additional structure to help guide our pursuit of one practice and its virtues over another. This structuring should be provided, he suggests, by a picture of the good life for a human being.

The good life for man is the life spent in seeking for the good life for man, and the virtues necessary for the seeking are those which will enable us to understand what more and what else the good life for man is (MacIntyre 1981: 219, emphasis added).

The virtues therefore are to be understood as those dispositions which will not only sustain practices and enable us to achieve the goods internal to practices, but which will also sustain us in the relevant kind of quest for the good, by enabling us to overcome the harms, dangers, temptations and distractions which we encounter, and which will furnish us with increasing self-knowledge and increasing knowledge of the good (MacIntyre 1981: 219).

The main role this conception of the good life plays in MacIntyre's thinking about the virtues, again, is helping us settle questions about which incompatible practices to devote ourselves to and about the relative importance of practices that can be pursued simultaneously. But given the variability of the ways in which people have conceived of "the good life for man" and the ways in which we can understand what this kind of life requires, it's still not clear that accepting a human telos alone can do the settling required. For example, one who views the good life along the lines of the life lived by the monk and one who views it along the lines of that of the soldier will likely structure their dedication to various practices quite differently, and so would also not agree on the characteristics that should be deemed virtuous

\footnotetext{
${ }^{32}$ (MacIntyre 1981: 191)
} 
and those that should be seen as vicious. ${ }^{33}$ The third part of MacIntyre's account aims at adjudicating this kind of disagreement.

The final part of the MacIntyrean story that allows us to give a definition of the virtues is the concept of a moral tradition (or a "tradition of inquiry" as it's called in Whose Justice? Which Rationality? ${ }^{34}$ ). MacIntyre's idea here is that one can't pursue or expect to justify answers to the question of what the good life for human beings is all alone. And he claims, further, that, in order to judge accounts of the good life, we need the establishment of historically located standards for what is to count as an adequate answer-standards that only emerge in the course of a tradition of inquiry defining and developing them. ${ }^{35,36}$ MacIntyre's notion of a tradition of inquiry that does this supporting and establishing work is roughly some common undertaking that's partly constituted by the arguments over what the undertaking itself should look like and what it should care about. A tradition is a "continuity of conflict" as he puts it in After Virtue $;{ }^{37}$ a "historically extended, socially embodied argument, and an argument precisely in part about the goods which constitute that tradition." 38 A moral tradition is in the business of seeking and justifying answers to the question of what is "the good and the best" kind of life human beings like us can lead. ${ }^{39}$ The justification of one tradition's answers to these questions necessarily involves comparing traditions insofar as they can answer other questions such as, "What resources does our particular tradition afford in this situation? Can we by means of those resources understand the achievements and successes, and the failures and sterilities, of rival traditions more adequately than their own adher-

\footnotetext{
${ }^{33} C f$. (MacIntyre 1981: 64).

${ }^{34}$ MacIntyre (1988)

${ }^{35}$ Making this case is one of the main goals of MacIntyre (1988).

${ }^{36}$ Moral traditions are also supposed to do some of the work of justifying something that might seem like a virtue: the virtue of understanding yourself and your place in a tradition. See (MacIntyre 1981: 223).

${ }^{37}$ (MacIntyre 1981: 222)

${ }^{38}$ (MacIntyre 1981: 222)

${ }^{39}$ (MacIntyre 1981: 275, emphasis in the original)
} 
ents can? More adequately by our standards? More adequately also by theirs?"40 It's only in confrontations like these that traditions as a whole can justify their answers to questions about the good/flourishing life, and through such confrontations MacIntyre hopes to show how traditions make progress towards reaching a more complete understanding of the virtues as well.

A virtue on MacIntyre's account can now be defined to be a trainable human quality that allows one to achieve the goods internal to practices and that helps one succeed in the pursuit of the good of a whole human life and that enables one to contribute to the maintenance and advancement of a tradition of inquiry.

\subsection{Tailoring the Account to Mathematics}

Although MacIntyre's account of virtue based on his understanding of practices, the structure of a human life, and the context of a moral tradition is formulated to deal primarily with ethical excellences, it very naturally can be adjusted to provide a framework for thinking about the wide variety of pursuits and excellences within mathematics and its practice. In fact, one of the most common objections to MacIntyre's line of thinking in virtue ethics (i.e., that there isn't a common good that we can take human life in general to aim at) looks like it becomes far less urgent when the expansive account is trimmed down to apply to a complex and varied, but not all-encompassing, stretch of human life such as mathematics. Obviously, it's not at all clear that there is or could be one overarching good at which mathematics aims, but that the conversation taking place between those pursuing the subject regarding what its goals are and should be could at least be hoped to reach something like agreement on this matter seems to be an easier hope to maintain. ${ }^{41}$

\footnotetext{
${ }^{40}$ (MacIntyre 1988: 402)

${ }^{41}$ See (Corfield 2012: 250-255) for an interesting attempt, also within a broadly MacIntyrean setting, to show that "perfected understanding" of mathematical objects is the overarching telos of mathematical research. See also Avigad (2008) on the general aim of understanding in mathematics.
} 
In order to have a framework for extracting virtues from mathematical practice that takes inspiration from MacIntyre's account above, we'll need something to play the role of each of the three background parts of that account. In place of practices in general, we can consider, e.g., the activities undertaken by fields and subfields as a whole; those of communities organized around a particular problem or problems; and the tasks of teaching, mentoring, researching, organizing or reorganizing, and popularizing. Instead of thinking about the good life for human beings in general, we might focus on the good life or career of a mathematician, or the good life or career of a particular type of mathematician. And, finally, the analogue of a moral tradition within mathematical practice might be taken to be something like those who take proof to require constructive methods, or those who aim to have all theorems be, in theory, formalizable within $Z F C$ or some form of type theory, or we could even consider the tradition of mathematics in, say, France as compared to Germany or Japan. Each of these aspects of mathematical life is embedded in human life more generally, so if MacIntyre's more general account of the virtues is correct, we can't separate the virtues of mathematics or mathematicians completely from general human virtues. Nevertheless, focusing on an account of the virtues qua mathematical by means of this general framework appears to bear fruit straightaway.

The first nice feature of this framework applied to mathematics is that it provides a convenient means of connecting the virtues of the mathematical practitioner and the virtues of the mathematical product by way of an account of the ongoing development of our understanding of the ends of various aspects of mathematical practice. A characteristic can be taken to be a virtue if it contributes to excellent achievement of the goods internal to, e.g., an area of the subject, while also contributing to the overall development of one sort of mathematician's life and mathematical tradition, where the goods, excellences, and good life are all understood according to that tradition's current best understanding of each of these. Conversely, a quality of a proof or definition or conjecture can be seen to be a virtue 
if it is something that's aimed at by the mathematical practitioner in her practice, career, or tradition according to the best current understanding of the ends of each of these within the tradition.

Next, the framework, by incorporating both local and global views of mathematical practice allows for investigations into one aspect of the overall practice to naturally reflect back on others. Consider first what might be learned by examining the local practices of, say, graph theorists, or those working in differential equations, or those involved in pursuing the Langlands program. In any given local practice, we'll expect to find some set of internal goods that may be specific or specifically valuable to that practice; e.g., solving interesting data-optimization problems, finding some piece of mathematics applicable to real-world problems, or finding some unifying connection across disparate subfields. The goods connected with some of these fields might group together naturally or not at all and so suggest different versions of what the good mathematician looks like and subsequently what the good mathematical life or career should be understood to be. These characteristics and understandings might then lead to the discovery of undercurrents of different traditions or conflicts within a tradition that could then be further brought out and clarified in ways that further discussions of the goals of the tradition or suggest the consideration of taking a new path. Attempting to come to an understanding of the virtues of mathematical practice or mathematical practitioners even quite locally could, therefore, lead directly to a deeper global understanding of the field.

The aim of conceptualizing stretches of mathematical practice as structured by what we consider to be the good mathematical career or life similarly allows for the raising of questions not commonly asked within the philosophy of mathematical practice: e.g., what makes a mathematical career a good and virtuous one? what are the goals appropriate to a mathematician at various stages in her development? G.H. Hardy had the controversial view that "[y]oung men should prove theorems, 
old men should write books," ${ }^{42}$ which there may be no real reason to accept, but that doesn't mean that different forms of mentorship, professional engagement, and so on might not be more or less virtuous at different points in a mathematician's life. ${ }^{43}$ These are not questions for philosophers to simply rule on obviously. But encouraging and engaging in the discussions in this area and the other areas that the MacIntyrean framework presented above suggest for investigation could perhaps lead to renewed relevance of philosophy of mathematics to mathematics itself: if we together find a picture of a good mathematical life or career within a tradition to be one that we judge to be unacceptable for one reason or another, we may aim to fix this by making changes to what's considered an excellence relative to the practice or tradition as a whole.

Finally, in relation to the interaction of local and global views, taking the most global perspective encouraged by MacIntyre's inclusion of the concerns of a tradition within his account of the virtues allows us to ask and try to answer questions about what makes one approach to the subject as a whole or in part thrive when another fails to do so. E.g., not everyone shares the concerns of Voevodsky (n.d.) about the need for formally verified proofs, but everyone can get excited about the new mathematics and applications of computer-assisted proofs that are under investigation in the univalent foundations program. ${ }^{44}$ This excitement is leading to renewed interest in type theory, and with it constructive mathematics more generally. How this is affecting mathematical practice as a whole is surely a question worth pursuing. If something like the MacIntyrean framework for understanding the virtues in the setting of mathematical practice presented here is on the right track, we should expect practitioners within the Voevodsky program and those outside of it to be considering the very questions MacIntyre suggests people in differing moral traditions should be considering when confronting one another:

\footnotetext{
${ }^{42}$ (Albers and Dyson 1994: 4)

${ }^{43}$ See, again, Jones (2006) for historical discussion of the question of how mathematics can develop a person's individual virtues.

${ }^{44}$ See Grayson (2018) for an introduction.
} 
"What resources does our particular tradition afford in this situation? Can we by means of those resources understand the achievements and successes, and the failures and sterilities, of rival traditions more adequately than their own adherents can? More adequately by our standards? More adequately also by theirs?"45,46 Answers to these questions can clearly impact both the more local practices of different areas of the subject as well as views about the good mathematical life more broadly.

I'll consider one final advantage of working within a MacIntyre-inspired framework when attempting to understand the virtues in mathematics, as well as a major objection to the view, before I move on to outline a methodology for pursuing the actual cataloguing of virtues within mathematical practice in Section 5. The advantage involves the fact that the framework is explicitly and self-consciously historical. The objection is that the view is hopelessly naïve about there being such a thing as the good mathematical life or career or a telos of the subject. I'll begin by considering the claimed-advantage first.

There are debates within mathematics about, for example, the use of different foundations or logics, which can seem to be decidable using reason alone or to not have a real effect on most of the ordinary practice of the subject. But there are also changes that affect everyone in the field regardless of their commitments, and these changes require some acknowledgement and incorporation into an understanding of the practice's state; e.g., pure mathematics is more influenced by physics now than it seems to have been previously; and research institutes are housing more mathematicians than ever before. ${ }^{47}$ This sort of fact is bound to have effects within the field itself and should be part of what "practice-first" philosophers of mathematics investigate. The proper way to integrate these new realities will likely require a good deal of thinking about which qualities of mathematical life

${ }^{46} C f$. MacIntyre (2006). See also (Corfield 2012: §5) for rich discussion of how conflicts between mathematical traditions might be settled from a MacIntyrean perspective.

${ }^{47}$ See National Research Council (2013) for more along these lines.
} 
and research are worth maintaining and which can be altered without too much loss when conflicts inevitably arise. By beginning with a historically-located understanding of mathematical practice and mathematical virtues, the shift to thinking about these more concrete historical realities is less abrupt than it would be if we began from a more isolated account of our subject.

The objection I'd like to consider next runs as follows. MacIntyre's framework applied to mathematics suffers from the same problem it suffers from more generally: it relies on a picture of the good life and the good itself when there just isn't any such thing to appeal to. That is, how could there be such a thing as the telos of mathematical practice itself or the good mathematical life overall? The subject is far too varied for there to be one end pursued, and it's not even clear that the characteristics and achievements that might make a mathematician successful in achieving particular goods are the same for one person as they travel from room to room in their department, let alone as they traverse a whole career or lifetime.

A full response to this objection would require a full defense of an understanding of inquiry and rationality as founded on the workings of a tradition. ${ }^{48}$ Nevertheless, the role of tradition in providing the means for responding to the objection can, I hope, be made plausible and palatable enough in outline that the overall approach to the virtues provided by a MacIntyrean account can be accepted independently of one's views about MacIntyre's longer story about justification and reason.

One important role for tradition in this MacIntyrean framework for the virtues is to help stabilize what we might expect to be the wildly varying opinions about the goods of various forms of mathematical practices and living. By attempting to give an account of how these goods and life projects fit into a picture of the good as currently best understood within a given tradition, one is forced to go beyond

\footnotetext{
${ }^{48}$ For MacIntyre's own attempts to justify his version of the claims of tradition-based inquiry, see, e.g., MacIntyre (1988), MacIntyre (1990), and most recently MacIntyre (2016). For more on the approach applied to mathematics, see again Corfield (2012).
} 
what could, without further reflection, be seen as nothing but subjective prejudice. Of course, a mathematician may not spend much time thinking about how to justify her value judgments from within her tradition. But to be genuinely part of a tradition is to take these sorts of questions at least somewhat seriously. Likewise, anyone working with a tradition of any sort would be expected to confront incoherence internal to the system they work with; to accommodate new discoveries or ideas; to respond to objections from other traditions or schools of thought internal to the tradition; and so on. ${ }^{49}$ If it's justifiable to think of the working mathematician as being part of some tradition of inquiry and if attempting to fit one's personal values and the values of the various mathematical practices one engages in into a form that can be justified from the perspective of one's location within something like a mathematical tradition can have a stabilizing effect-and it seems to be the case that both of these are plausibly the case-then the extreme variation posited by the objection can be mitigated to some degree. This mitigation makes it possible for inquiry into the virtues within a MacIntyrean framework to proceed in the worst case by acting as if there were objective goods at which to aim. This starting point is enough to still allow the framework to provide guidance and structure for our study of the virtues within mathematics.

\section{Viewing Mathematical Practice Realistically}

Having now characterized mathematical practice as an epistemic, objectual practice in the sense of Knorr Cetina and provided a MacIntyrean framework for investigating virtue-based aspects of the practice, I'll further suggest several methodological principles that should be employed in the actual investigation of the practice within this framework. ${ }^{50}$ The methodological position I'll be advocating is

\footnotetext{
49(MacIntyre 2016: 206)

${ }^{50}$ (Rittberg 2019: 13) provides a long list of possible methodologies for pursuing the study of mathematical practice. The approach advocated here is closest to the one mentioned from Larvor
} 
most naturally called "realist," but it warrants this label simply by being realist in the everyday, non-philosophical sense of the word. In order to avoid the confusion of this ordinary realism with its more familiar philosophically and metaphysically realist competitors, I'll instead refer to the methodological principles discussed in this section as being "realistic." I contend that this is the only kind of realism that philosophers of mathematics have any need to subscribe to. Having provided a more complex view of the practice of mathematics, a framework within which to consider this practice's virtues, and a methodology with which to pursue the study of concrete virtues within the practice, I'll claim that the prolegomena to virtuetheoretic studies in the philosophy of mathematics planned to be undertaken here are completed.

In philosophical work, the most familiar advocates of a realistic methodology of the type to be described in this section have pursued practical questions in legal and political philosophy. In Philosophy and Real Politics, for instance, Raymond Geuss expounds a realistic methodology that enjoins the political philosopher to inquire into political thought and action with the aim of discounting illusory motivations and goals by ignoring idealizations and rational reconstructions. Instead, he urges political philosophers to study the concrete realities that have actually motivated real human actors as they have pursued their definite social and political goals. Geuss's realist offers the guidance, "Don't look just at what they say, think, believe, but at what they actually do, and what actually happens as a result." ${ }^{, 51}$ By investigating real actions rather than the principles that purport to motivate and justify these actions, the realistic philosopher strives to strip away whatever obfuscation and ideology they can in order to get at the real mechanics of power and (2010), but it's not my intention to rule out any of the alternatives. Rather, the methodology to be considered simply suggests ways of thinking about the various objects of study focused on by these other approaches. I should note also that the approach doesn't fit very naturally into the catalogue of (Van Bendegem 2014: 221).

${ }^{51}$ See (Geuss 2008: 10, emphasis in the original). This kind of thinking is also prominent in the work of Max Weber; see, e.g., (Weber 1968: Part 2, Ch. X). 
legitimacy in the realm of politics. This is a paradigm case of taking a realist's approach to a subject-realist, in the ordinary sense of the word. ${ }^{52}$

Contemporary philosophy of mathematics has rightly moved in the direction of attempting to pay closer attention to the ordinary practice of mathematics. This trend may suggest that the subject has also already accepted a realistic methodology of the sort just indicated. This has not really been the case, however. Too much weight is still placed on the psychology of mathematicians and the analysis of philosophical offerings found lurking around a mathematician's proofs or tucked away in her prefaces. There remains, therefore, a need within the field for the adoption of a methodology that is realistic in a sense analogous to the ones employed in some of the more familiar arenas of realistic thought discussed above. At any rate, the primary goal of this section is to make the case for the usefulness of this methodological position.

The philosopher who has previously been most adamant about practicing the kind of ordinary realism to be advocated here when thinking about mathematics is (the later) Wittgenstein. ${ }^{53}$ I'll, therefore, look to Wittgenstein for inspiration as I outline the main tenets of the realistic methodology for examining mathematical practice within the framework I'm proposing. The following two subsections will introduce what I take to be two of the most important of Wittgenstein's insights and then expand on how they might be employed in the study of mathematical practice. I'll also suggest how these methods can be used to help avoid a mistake it might otherwise be easy to make when trying to come to an understanding of mathematicians' own conception of mathematical virtues.

Before moving on to this discussion, however, I should pause to note the seeming oddness of pairing Wittgenstein's thought with what's come before. For ex-

\footnotetext{
${ }^{52}$ The American legal realists can be seen as being realistic in a similar way. See, for example, (Leiter 2005: 50-53).

${ }^{53} C f$. (Wittgenstein 1939/1989: 55, 103). It remains a matter of controversy, however, whether Wittgenstein really wanted nothing more than for us to look at the workings of mathematics "from close to" (Wittgenstein 1953/2009: §51, emphasis in the original).
} 
ample, my account of mathematical practice as objectual seems to be opposed to Wittgenstein's thinking about mathematics, which is often presented as being antirealist. ${ }^{54}$ Further, a full MacIntyrean account of the mathematical virtues would proceed methodically towards objective goods through careful rational reconstruction of practice and tradition, while Wittgenstein seems most concerned with how to go on quickly in the short run and doesn't think that there are objective truths about the world of mathematics to mirror in our understanding of mathematical practice.

While it's true that Wittgenstein is often associated with a form of anti-realism and would likely not find MacIntyre's method for justifying a particular good as the good appealing, this association and fact are ultimately orthogonal to the role Wittgenstein's ideas will play in the methodological account to be presented in this section. That is, it's perfectly possible to take mathematics to be about objects or not, while still employing a realistic methodology inspired by Wittgenstein to investigate an objectual practice. Similarly, while the MacIntyrean framework for investigating the virtues does require a quality to contribute to the maintenance of tradition for it to count as a virtue, the inquiry into which qualities are most prominent within a given practice and which do this kind of contributing can be carried out using a methodology inspired by Wittgenstein regardless of whether or not Wittgenstein himself would find contribution to the maintenance of a mathematical tradition to be something worth caring about. The best recent work on Wittgenstein's writings in the philosophy of mathematics has in fact moved away from trying to categorize him as an advocate of any particular "-ism" and has instead emphasized the realistic methodology in the sense to be explained often on display in his writings. ${ }^{55}$ It's within this recent trend in Wittgenstein scholarship that the appeal to Wittgenstein's thought in this paper should be situated. Being situated within the context of this trend makes the conclusions Wittgenstein him-

\footnotetext{
${ }^{54}$ See, e.g., (Dummett 1959: 348) for the classic interpretation of this kind.

${ }^{55}$ See in particular the work of Juliet Floyd and Felix Mühlhölzer in the bibliography.
} 
self might've reached using his methods, which I'm not aiming to defend here, largely unimportant. With these preliminary worries addressed, then, I'll move on to outlining the realistic methodology I'm recommending.

\section{1 "If you want to know what has been proved, look at the proof." 56}

One of Wittgenstein's most well-known pieces of advice for taking a realistic view of mathematics and mathematical practice is to take care to distinguish between prose and proof when reading mathematical writing. He suggests that mathematics expressed in prose is more likely to be misleading or to be used in the service of suspect metaphysical projects_-and he thinks this to be true of any prose interpretation. Wittgenstein's suggestion, "If you want to know what has been proved, look at the proof," is the most straightforward way to try to act on any skepticism about prose in mathematical writing. However, the suggestion calls for expansion and modification since it's not at all clear how to act on in practice it and since it looks like it commits one to a kind of "proof chauvinism" that could lead to the overlooking of many important and interesting aspects mathematical practice relevant to the virtues. ${ }^{57}$ The goal of only addressing misleading prose and not actual mathematics makes the question of how the two can be clearly distinguished a pressing one. Many interpreters of Wittgenstein's work have found drawing the distinction to be no simple matter, and for good reason. ${ }^{58}$ It is, however, important to note before moving on that prose and proof can't be separated as easily as by looking for one outside and the other inside of a "Proof: ... Q.E.D."-pair.

One way of expanding on this first insight of Wittgenstein's when trying to

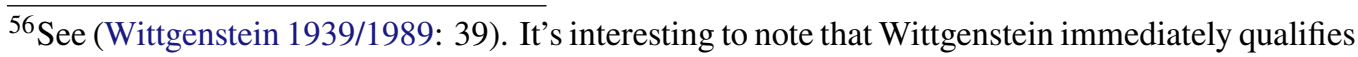
this claim, calling it an exaggeration and saying that it's partly true and partly false.

${ }^{57}$ The term 'proof chauvinism' comes from D'Alessandro (2018), which argues that not every mathematical explanation is a proof. Lange (2017) addresses this topic as well.

58 See, e.g., Floyd (2001) and (Kienzler and Grève 2016: 81). 
understand the virtues of a mathematical product and of acting on a skepticism about prose interpretations of mathematical results can perhaps be brought out most clearly by considering an analogy with the investigations of reverse mathematics. Reverse mathematics is a subfield of mathematical logic initiated by the work of Harvey Friedman in the 1970s that takes as one of its main goals the determination of minimal axiom systems required to prove standard mathematical theorems. ${ }^{59}$ An axiom system is taken to be of the minimal strength required to prove a theorem if $(i)$ the theorem can be proved from the axioms (over a weak base logic) and (ii) the axioms can be proved from the assumption of the theorem as well. The proof involved in demonstrating (ii) is where the 'reverse' comes from in the name: there's a sense in which we're going backwards if we start from a theorem and use it to prove an axiom. By finding the minimal setting in which a given theorem can be proven, we can hope to get some sense of that theorem's real strength or content. Similarly, by making minimal philosophical assumptions about the correct way to think about a mathematical object or theorem, it may be possible to find the minimal thing or things that must be said in order to comprehend that mathematical object or construction or to make sense of that particular result. The claims that look like they can't be denied can at least be hoped to be free from the sorts of problems endemic to other more elaborate prose interpretations, and could arguably be considered to contain the real mathematical content involved in a given case. ${ }^{60}$ The attempt to isolate something approaching the real mathematical content of the item of interest should be seen as the necessary first step towards understanding its mathematically virtuous features.

According to Wittgenstein, a realistic look at mathematics will reveal that

\footnotetext{
${ }^{59}$ See, e.g., Friedman (1975) and Simpson (1999), which is the standard reference.

${ }^{60}$ The attempt to minimize philosophical background assumptions also helps to make room for the "pluralism in perspectives" suggested by Michelle Friend, another author that can be seen as attempting to find the best way to be realistic when philosophizing about mathematics. See (Friend 2014: 25).
} 
"mathematics is a MULTICOLOURED mixture." 61 On one way of understanding it, this "mixture"-perspective of mathematics is almost a truism. We clearly do use different proof methods with differing frequencies when doing, say, combinatorics as compared to real analysis or algebra or set theory. Working with categories versus sets or the rationals versus the reals can feel like working with significantly different species of mathematical object. And when we look at the "normal science" of mathematics, we undeniably see different goals and methods, and this fact should be taken seriously as we approach the subject from a philosophical angle.

So, for example, number theory is out to investigate a potentially infinite sequence; algebra is in the business of identifying and studying structural features shared by many mathematical objects; analysis grew out of scientific applications and focuses on real number spaces and their generalizations; at least one aim of set theory is to provide a certain kind of foundation for classical mathematics. Each of these endeavors involves different methods, different ways of thinking, and these appear to be differences 'in the math' (Ernst et al. 2015: 159). ${ }^{62}$

Despite these points in its favor, however, this claim of Wittgenstein's is often taken to be one of his most controversial mathematical remarks. Philosophers and mathematicians alike have taken exception to this line of thought, perhaps because they have taken him to be denying some kind of underlying unity of the subject. John Burgess, for example, explicitly argues that "[m]athematics is no motley." 63 And the Fields medalist Jean-Pierre Serre exemplifies a common conception of the

\footnotetext{
${ }^{61}$ This is Felix Mühlhölzer's translation of the passage more familiarly rendered as "Mathematics is a motley" (Wittgenstein 1956/1983: III §46). Mühlhölzer argues that the term 'motley' has negative connotations that don't fit well with the general thrust of Wittgenstein's remarks about the mixture of proof methods found in mathematics. I use his translation of this remark to signal my agreement on this point. See, however, (Hacking 2014: 57) for a contrary view.

${ }^{62} C f$. (Ferreirós 2016: 37).

${ }^{63}$ (Burgess 2015: 60)
} 
unity of mathematics when he states that many important mathematical questions "are not group theory, nor topology, nor number theory: They are just mathematics." $" 64$

This natural objection to Wittgenstein illustrates clearly the value of taking a realistic perspective when thinking about mathematical practice, especially when the various values and goods of different practices are in question. To say that mathematics is a patchwork of proof methods and systems isn't to deny that there are connections and similarities of methods and questions to be found all over the subject, often in surprising places. Nor is it to deny that some of the most important and deep problems of contemporary research can't be nicely separated into group theory or analysis or topology alone. In fact, one of the things that most interests Wittgenstein about mathematics — and that inevitably interests anyone acquainted with the subject at all-is the myriad and unexpected ways in which what may be (or may appear to be) different areas of mathematics come to be linked together and integrated over time. ${ }^{65}$ Wittgenstein himself often makes the further claim that these links and connections are created rather than discovered, ${ }^{66}$ and this does imply that there isn't a pre-established world of mathematics revealed by mathematical research. In my estimation, it's this further claim that most rankles when it comes to this topic. The further, stronger claim is suggested, not just by Wittgenstein, but by the tenet of the realistic methodology on offer here that tries to make minimal philosophical assumptions whenever possible, but it's not required or something that must be enforced for those who wish to take a realistic view of the subject. In particular, one need not make such a strong further claim when being guided by the thought that viewing mathematics realistically reveals a multicolored mixture of proof methods and practices whose different perspectives

\footnotetext{
64(Serre et al. 1999: 35)

${ }^{65}$ See, e.g., (Wittgenstein 1956/1983: I §166): "What, then—does [mathematics] just twist and turn within these rules?-It forms ever new rules: is always building new roads for traffic; by extending the network of the old ones." See also (Wittgenstein 1956/1983: III §31).

${ }^{66}$ E.g., (Wittgenstein 1930/1975: §158) and (Wittgenstein 1956/1983: I §168).
} 
on the mathematical virtues must be respected if we're to obtain an adequate view of the subject.

\section{2 "[I]f we had to name anything which is the life of the sign, we should have to say it was its use." 67}

Wittgenstein characterizes Frege as claiming that, if the formalists are correct that "[a]rithmetic is concerned only with the rules governing the manipulation of the arithmetical signs, not, however, with the reference of the signs," ${ }^{68}$ the signs used in mathematics "would be dead and utterly uninteresting, whereas they obviously have a kind of life." 69 He returns to the metaphor of live and dead signs often in his writings. For example, the following exchange in the Investigations again connects the idea of a living sign with the concept of use: "Every sign by itself seems dead. What gives it life?-In use it is alive."70 The second major imperative of the realistic methodology being advocated in this section is to aim to always view mathematical practice in its live, rather than dead, form.

The importance of use in bringing mathematical expressions to life according to Wittgenstein's picture of meaning can be brought out by way of the claim that we often get ourselves into philosophical tangles when we view language apart from its use-when language goes "on holiday."71 Wittgenstein suggests that we often find questions about the meaning of specific words or propositions taken out of context difficult or impossible to answer, but, when live and in use, any hesitation about what a word or phrase means for the most part seems to vanish instantly. This is evidently the basic point of the following passage.

\footnotetext{
${ }^{67}$ (Wittgenstein 1935/1958: 4, emphasis in the original)

${ }^{68}$ See (Frege 1903/1960: §88). This is Frege's way of restating the views of E. Heine and

J. Thomae.

${ }^{69}$ (Wittgenstein 1935/1958: 4)

${ }^{70}$ (Wittgenstein 1953/2009: $\$ 432$, emphasis in the original)

71 (Wittgenstein 1953/2009: §38)
} 
If I am drowning and I shout "Help!", how do I know what the word Help means? Well, that's how I react in this situation. - Now that is how I know what "green" means as well and also know how I have to follow the rule in the particular case (Wittgenstein 1956/1983: VI $\S 35$, emphasis in the original).

Wittgenstein's general hope is that many, if not all, of our philosophical difficulties can be resolved if we can "bring words back from their metaphysical to their everyday use" where they function without fault. ${ }^{72,73}$ For the purposes of this paper, the resolution of philosophical difficulties is of less concern than the hope that by restricting our observation of mathematics and its practice to times when signs and techniques are in use, we'll have a more accurate picture of the true values and virtues in play.

The general principle of allowing the meaning of a term or proposition to be illuminated by how it's used is clear enough and one that seems to have already appeared broadly plausible to mathematicians and philosophers of mathematics. For example, William Thurston, another Fields medalist reflecting on his subject, suggests that the language of mathematics "is not alive except to those who use it,"74 and Stewart Shapiro and Hilary Putnam both subscribe to a "Use Thesis" that is Wittgensteinian in content. ${ }^{75}$ However, there are still a few points worth emphasizing about this tenet of the realistic methodology before moving on to a brief illustration of its usefulness.

The first thing to notice is the fact that the languages of mathematics aren't always used like ordinary languages are, so there may be some question about what

\footnotetext{
${ }^{72}$ (Wittgenstein 1953/2009: §116)

${ }^{73}$ What exactly 'metaphysical' is supposed to mean in this statement is the matter of a debate that needn't be settled here. For the record, I'm roughly in agreement with Gordon Baker, who suggests that metaphysical uses try to express essences or to pass themselves off as being scientific but are not. $C f$. (Baker 2009: 96-100).

${ }^{74}$ (Thurston 2006: 167)

${ }^{75}$ See (Shapiro 1991: 212) and Putnam (1980).
} 
this kind of language's being in use is supposed to look like. This is a reasonable concern, but some ground can be gained towards understanding mathematical language in use by employing the via negativa.

When doing ordinary mathematics and logic, giving an "interpretation" of a language means setting up a map between the symbols of the language and some appropriate mathematical structure. Given this way of thinking about interpretations, it's easy to think that questions about meaning and reference can be investigated using these simple model-theoretic methods. However, as Mühlhölzer (2014) rightly points out, when we give an interpretation, we precisely aren't using the language in question-we're instead constructing a further mathematical object. If that's correct and if meaning essentially has to do with use as Wittgenstein believes, then this kind of construction has nothing at all to do with meaning. One way to focus on the importance of use in observing mathematical practice, then, is to be careful not to allow talk of interpretations in the model-theoretic sense to be uncritically used to settle questions about meaning and other closely related issues. More generally, it may be easier to tell when a language is not being used than to give a full account of what exactly being in use requires or entails. Fortunately, in many cases this is enough.

Secondly, it's worth remembering that not every question about use needs to be put simply in terms of whether or not a sign or expression is being used. We can also ask about how these linguistic items are put to use. For example, perhaps upon close examination, the axioms that define a particular area of inquiry look as if they function like rules for the use of the terms involved, as is concluded in Friederich (2011). Maybe certain theorems appear to function in this way as well when they're put to use. For example, the Bolzano-Weierstraß theorem states that any bounded sequence in $\mathbb{R}^{n}$ has a convergent subsequence. This theorem is often used like a rule that licenses one to conclude that such a convergent subsequence is already in hand. If we pay close attention to the ways in which theorems, lemmas, and axioms are put to use in ordinary circumstances, we should be able to command a 
clearer view of the subject and its practices, again even without a fully worked out theory of mathematical use.

Consider the following example of how this part of the realistic methodology being advocated can be put to good use. One of the pressing questions the philosophy of mathematical practice must answer is, "What is the real extent of agreement among mathematicians within the practice?" Appeals to "mathematical practice" make it seem as if there is some kind of monolithic consensus being relied on, but so far this consensus has largely been simply assumed. In a pair of useful publications, Matthew Inglis and Andrew Aberdein have attempted to provide some empirical data relating to this question. ${ }^{76}$ Inglis and Aberdein (2016) selected a proof from Aigner and Ziegler (2000) and asked 53 research mathematicians from Australia, Canada, and New Zealand to determine (on a 5-point scale) how well twenty adjectives like 'ingenious', 'difficult', 'shallow', 'rigorous', and 'informative' applied to the proof. They interestingly found that four broad dimensions - aesthetics, intricacy, precision, and utility-could in linear combination approximate many of the adjectives they used; e.g., "proofs were likely to be rated as explanatory if they were useful, precise and non-intricate." 77 They also found "a remarkable level of disagreement" between the participants' evaluations of the proof. What should we make of this disagreement?

Someone accepting a realistic methodology of the sort advocated in this section would suggest that we should be very wary of inferring anything at all from these data. Why? First, if a realist is someone who looks "not at what they say, but at what they do," a mathematician's using a particular adjective to describe a proof on its own shouldn't lead a realist to conclude that, say, a particular proof is explanatory. Instead, the advocate of a realistic methodology would prefer to find cases where a mathematician was asked for an explanation of some fact and presented a proof as explanatory in that context. She'd further only take the fact that

\footnotetext{
${ }^{76}$ Inglis and Aberdein (2015), Inglis and Aberdein (2016)

${ }^{77}$ (Inglis and Aberdein 2016: 168)
} 
this proof was presented as explanatory to reveal that the proof is explanatory in this context rather than explanatory tout court. Second, and this worry is related to the first, asking a mathematician to evaluate a proof on a questionnaire looks like a paradigm case of investigating language "on holiday." It's asking what Baz (2012) calls "the theorist's question": does our concept of $x$ apply to some real or imaginary case. If our aim is to investigate mathematical practice realistically, we should look for ways of investigating how these concepts are applied when they're really being used and when the applications have a point. Baz rightly points out that generally, "the point of an everyday question guides us in answering it and in assessing our own and other people's answers, [but] this guidance is lacking when the theorist invites us to answer his question."78 Not only is the language likely to be on holiday in this kind of situation, but the mathematician might be on holiday too in essence. If virtues must be understood relative, in part, to practices, then an individual mathematician isn't the locus for revealing the value of a particular proof. That same mathematician might find the proof, say, explanatory in the context of one practice and not in the context of another. Clearly, philosophers of mathematics interested in understanding mathematical practice have to do something like the kind of empirical work Inglis and Aberdein are attempting, but perhaps we need to rethink the methods used in collecting this kind of information. ${ }^{79}$ Finding uses of the various ways of speaking about the virtues a

\footnotetext{
${ }^{78}$ (Baz 2012: 105)

${ }^{79}$ The methodological principles advocated in this section are similar to those accepted in ethnomethodology and the sociology of scientific knowledge. (See, e.g., (Livingston 1986: 1), (Lynch 1993: 14-15), and more recently François and Van Kerkhove (2010) for ethnomethodology. Barnes et al. (1996) is a good example of the sociology of knowledge that deals with mathematics in its final chapter.) Many of the authors within these fields also take inspiration from Wittgenstein, so the resemblance isn't coincidental. The goal of "pure description" for which ethnomethodologists put this kind of methodology to use is, however, likely to be different from the goals of philosophers of mathematics who make use of the methodology outlined here. Being a methodology though, the realistic view on offer doesn't seek to dictate the uses to which it's put.
} 
mathematical proof might possess "in the wild" (i.e., while really in use) is likely to give us a better picture of the way these dimensions of a proof are evaluated and put us in a better position to understand the way the practice views virtuous performances of proving.

\section{Further Questions and Conclusions}

Philosophers of mathematics have often aimed to better understand portions of mathematical practice by first looking for the virtues particular mathematicians see in some piece of mathematics. Revealing the practice through its values is often the point of talking about virtues in relation to mathematics in the first place. If what's been said here is on the right track, an investigation of at least some of the main structural features of the practice should, instead, come first. Looking closely at practice using a realistic methodology and a rich framework within which virtues can disclose themselves rather than assuming a collection of virtues that apply to the mathematical domain at the outset reveals numerous places where virtuetheoretic thinking can play a role that might easily be overlooked otherwise. Seeing mathematical practice as being an epistemic, objectual practice involved in dealing with a massive knowledge base leads to numerous questions about how to cope with this ever-expanding resource and about how to produce mathematicians who can virtuously cope with the expansion. Seeing mathematical practice as dynamic and extending across traditions allows us to ask questions such as: What conditions favor development or stagnation in a field? or What kinds of arguments are used to get others to accept a conceptual variant or reject it over time? ${ }^{80}$ Answers to these questions can reveal perhaps unexpected virtues of mathematical environments and products. Thinking in terms of the characters and careers of mathematical practitioners allows us to ask how the goals of the discipline impose demands and traits on those involved in mathematical practice and how the characteristics of

${ }^{80} C f$. (Toulmin 1972: 505-506) 
those that enter the discipline shape the goals of a given subject. ${ }^{81}$ Finally, taking a realistic view of the practice can help safeguard us from following false leads and jumping to conclusions, but it also poses the problem of finding data and evidence that can be used reliably. There have been more than enough calls to action for philosophers of mathematics and its practice to remedy theoretical problems of various sorts. I've tried to do more than just raise a call here, but clearly there's still a lot to be done.

\section{References}

Aigner M, Ziegler G (2000) Proofs from THE BOOK. Springer

Albers D, Dyson F (1994) Freeman dyson: Mathematician, physicist, and writer. The College Mathematics Journal 25(1):2-21

Avigad J (2008) Understanding proofs. In: Mancosu P (ed) The Philosophy of Mathematical Practice, Oxford University Press

Baker A (2009) Mathematical accidents and the end of explanation. In: Bueno O, Linnebo $\varnothing$ (eds) New Waves in Philosophy of Mathematics, Palgrave Macmillan

Barnes B, Bloor D, Henry J (1996) Scientific Knowledge: A Sociological Analysis. University of Chicago Press

Baz A (2012) When Words Are Called For: A Defense of Ordinary Language Philosophy. Harvard University Press

Bourdieu P (1977) Outline of a Theory of Practice. Cambridge University Press

Burgess J (2015) Rigor and Structure. Oxford University Press

Burian RM (2001) The dilemma of case studies resolved: The virtues of using case studies in the history and philosophy of science. Perspectives on Science 9(4):383-404

Carter J (2019) Philosophy of mathematical practice - motivations, themes and prospects. Philosophia Mathematica (III) 27(1):1-32

Cellucci C (2013) Top-down and bottom-up philosophy of mathematics. Foundations of Science 18(1):93-106

${ }^{81} C f$. (Toulmin 1972: 507-508) and Henriksen (1993). 
Corfield D (2012) Narrative and the rationality of mathematical practice. In: Doxiadis A, Mazur B (eds) Circles Disturbed: The Interplay of Mathematics and Narrative, Princeton University Press

D’Alessandro W (2018) Mathematical explanation beyond explanatory proof. British Journal for the Philosophy of Science

Davis P, Hersh R (1981) The Mathematical Experience. Houghton Mifflin

Diamond C (1996) Wittgenstein, mathematics, and ethics: Resisting the attractions of realism. In: The Cambridge Companion to Wittgenstein, Cambridge University Press

Dummett M (1959) Wittgenstein's philosophy of mathematics. Philosophical Review 68(3):324-348

Dunne J (2005) An intricate fabric: Understanding the rationality of practice. Pedagogy, Culture and Society 13(3):367-389

Ernst M, Heis J, Maddy P, McNulty M, Weatherall J (2015) Forward to special issue on mathematical depth. Philosophia Mathematica (III) 23(2):155-162

Ferreirós J (2016) Mathematical Knowledge and the Interplay of Practices. Princeton University Press

Floyd J (2001) Prose versus proof: Wittgenstein on gödel, tarski and truth. Philosophia Mathematica (III) 9(3):280-307

Floyd J (2011) On being surprised: Wittgenstein on aspect-perception, logic, and mathematics. In: Day W, Krebs V (eds) Seeing Wittgenstein Anew: New Essays on Aspect Seeing, Cambridge University Press

Floyd J (2012) Das Überraschende: Wittgenstein on the surprising in mathematics. In: Ellis J, Guevara D (eds) Wittgenstein and the Philosophy of Mind, Oxford University Press

Floyd J (2015) Depth and clarity. Philosophia Mathematica (III) 23(2):1-22

Font V, Godino J, Gallardo J (2013) The emergence of objects from mathematical practices. Educational Studies in Mathematics 82(1):97-124

François K, Van Kerkhove B (2010) Ethnomathematics and the philosophy of mathematics (education). In: Löwe B, Müller T (eds) PhiMSAMP. Philosophy of Mathematics: Sociological Aspects and Mathematical Practice, College Publications

Frege G (1903/1960) Grundgesetze der Arithmetik, vol. II. In: Geach P, Black M (eds) Translations from the Philosophical Writings of Gottlob Frege, Basil Blackwell

Friederich S (2011) Motivating wittgenstein's perspective on mathematical sentences as norms. Philosophia Mathematica (III) 19(1):1-19 
Friedman H (1975) Some systems of second order arithmetic and their use. In: Proceedings of the International Congress of Mathematicians (Vancouver, 1974), vol 1, Canadian Mathematical Congress

Friend M (2014) Pluralism in Mathematics: A New Position in Philosophy of Mathematics. Springer

Geuss R (2008) Philosophy and Real Politics. Princeton University Press

Grayson D (2018) An introduction to univalent foundations for mathematics. Bulletin of the American Mathematical Society 55(4):427-450

Grosholz E (2007) Representation and Productive Ambiguity in Mathematics and the Sciences. Oxford University Press

Hacking I (2014) Why Is There Philosophy of Mathematics at All? Cambridge University Press

Harris C, Pritchard M, James R, Englehardt E, Rabins M (2019) Engineering Ethics: Concepts and Cases. Cengage

Heidegger M (1927/1962) Being and Time. Basil Blackwell

Henriksen M (1993) There are too many b.a.d. mathematicians. The Mathematical Intelligencer 15(1):6-9

Hicks D, Stapleford T (2016) The virtues of scientific practice: Macintyre, virtue ethics, and the historiography of science. Isis 107(3):449-472

Inglis M, Aberdein A (2015) Beauty is not simplicity: An analysis of mathematicians' proof appraisals. Philosophia Mathematica (III) 23(1):87-109

Inglis M, Aberdein A (2016) Diversity in proof appraisal. In: Larvor B (ed) Mathematical Cultures: The London Meetings 2012-2014, Birkhäuser

Jones M (2006) The Good Life in the Scientific Revolution: Descartes, Pascal, Leibniz, and the Cultivation of Virtue. University of Chicago Press

Kienzler W, Grève S (2016) Wittgenstein on gödelian 'incompleteness,' proofs and mathematical practice: Reading Remarks on the Foundations of Mathematics, part i, appendix iii, carefully. In: Grève S, Jakub M (eds) Wittgenstein and the Creativity of Language, Palgrave Macmillan

Kitcher P (1984) The Nature of Mathematical Knowledge. Oxford University Press

Knorr-Cetina K (1981) The Manufacture of Knowledge: An Essay on the Constructivist and Contextual Nature of Science. Pergamon Press

Knorr Cetina K (1999) Epistemic Cultures: How the Sciences Make Knowledge. Harvard University Press 
Knorr Cetina K (2001) Objectual practice. In: Schatzki T, Knorr Cetina K, von Savigny E (eds) The Practice Turn in Contemporary Theory, Routledge

Lange M (2010) What are mathematical coincidences (and why does it matter)? Mind 119(474):307-340

Lange M (2017) Mathematical explanations that are not proofs. Erkenntnis 83(8):1-18

Larvor B (2001) What is dialectical philosophy of mathematics? Philosophia Mathematica (III) 9(2):212-229

Larvor B (2010) Syntactic analogies and impossible extensions. In: Löwe B, Müller T (eds) PhiMSAMP_Philosophy of Mathematics: Sociological Aspects and Mathematical Practice, College Publications

Laugier S (2013) Why We Need Ordinary Language Philosophy. University of Chicago Press

Leiter B (2005) American legal realism. In: Golding M, Edmundson W (eds) The Blackwell Guide to the Philosophy of Law and Legal Theory, Blackwell Publishing

Livingston E (1986) The Ethnomethodological Foundations of Mathematics. Routledge \& Kegan Paul

Lynch M (1993) Scientific Practice and Ordinary Action: Ethnomethodology and Social Studies of Science. Cambridge University Press

MacIntyre A (1981) After Virtue: A Study in Moral Theory. University of Notre Dame Press

MacIntyre A (1988) Whose Justice? Which Rationality? University of Notre Dame Press

MacIntyre A (1990) Three Rival Versions of Moral Enquiry: Encyclopaedia, Genealogy, and Tradition. University of Notre Dame Press

MacIntyre A (2006) Epistemological crises, dramatic narrative, and the philosophy of science. In: The Tasks of Philosophy: Selected Essays, v. 1, Cambridge University Press

MacIntyre A (2016) Ethics and the Conflicts of Modernity: An Essay on Desire, Practical Reasoning, and Narrative. Cambridge Universtiy Press

Mazur B (1997) Conjecture. Synthese 111(2):197-210

Methven S (2015) Frank Ramsey and the Realistic Spirit. Palgrave Macmillan

Mühlhölzer F (2002) Wittgenstein and surprises in mathematics. In: Haller R, Puhl K (eds) Wittgenstein and the Future of Philosophy: A Reassessment after 50 Years, öbt $\& \mathrm{hpt}$

Mühlhölzer F (2010) Braucht die Mathematik eine Grundlegung? Eine Kommentar des 
Teils III von Wittgenstein Bermerkungen über die Grundlagen der Mathematik. Vittorio Klostermann

Mühlhölzer F (2014) On live and dead signs in mathematics. In: Link G (ed) Formalism and Beyond: On the Nature of Mathematical Discourse, De Gruyter

National Research Council (2013) Important trends in the mathematical sciences. In: The Mathematical Sciences in 2025, The National Academies Press

Pitt JC (2001) The dilemma of case studies: Toward a heraclitian philosophy of science. Perspectives on Science 9(4):373-382

Putnam H (1980) Models and reality. Journal of Symbolic Logic 45(3):464-482

Radford L (2008) The ethics of being and knowing: Towards a cultural theory of learning. In: Radford L, Schubring G, Seeger F (eds) Semiotics in Mathematics Education: Epistemology, History, Classroom, and Culture, Sense Publishers

Rittberg CJ (2019) On the contemporary practice of philosophy of mathematics. Acta Baltica Historiae et Philosophiae Scientiarum 7(1):5-26

Rouse J (2003) How Scientific Practices Matter: Reclaiming Philosophical Naturalism. University of Chicago Press

Sartre JP (1943/1993) Being and Nothingness: An Essay on Phenomenological Ontology. Washington Square Press

Schatzki T (1996) Social Practices: A Wittgensteinian Approach to Human Acitivity and the Social. Cambridge University Press

Serre JP, Chong CT, Leong Y (1999) An interview with jean-pierre serre. In: Wilson R, Gray J (eds) Mathematical Conversations: Selections from The Mathematical Intelligencer, Springer

Shanker S (1987) Wittgenstein and the Turning-Point in the Philosophy of Mathematics. Routledge

Shapiro S (1991) Foundations without Foundationalism: A Case for Second-order Logic. Oxford University Press

Simpson S (1999) Subsystems of Second Order Arithmetic. Springer

Soler L (2012) Préface to "from practice to results in logic and mathematics" issue. Philosophia Scientiae 16(1):1-3

Su F (2020) Mathematics for Human Flourishing. Yale University Press

Tanswell FS (2016) Proof, Rigour and Informality: A Virtue Account of Mathematical Knowledge. Ph.D. Dissertation, University of St. Andrews

Thurston W (2006) On proof and progress in mathematics. In: Hersh R (ed) 18 Uncon- 
ventional Essays on the Nature of Mathematics, Springer

Toulmin S (1972) Human Understanding, vol. I: General Introduction and Part I. Clarendon Press

Van Bendegem J (2014) The impact of the philosophy of mathematical practice on the philosophy of mathematics. In: Soler L, Zwart S, Lynch M, Israel-Jost V (eds) Science After the Practice Turn in the Philosophy, History, and Social Studies of Science, Routledge

Van Bendegem JP, Van Kerkhove B (2004) The unreasonable richness of mathematics. Journal of Cognition and Culture 4(3):525-549

Voevodsky V (n.d.) Unimath. HFL 2015, 25 August 2015, Heidelberg

Weber M (1968) Economy and Society: An Outline of Interpretive Sociology. University of California Press

Wittgenstein L (1930/1975) Philosophical Remarks. Basil Blackwell

Wittgenstein L (1935/1958) The Blue and Brown Books: Preliminary Studies for the Philosophical Investigations. Blackwell

Wittgenstein L (1939/1989) Wittgenstein's Lectures on the Foundations of Mathematics, Cora Diamond, (ed.). University of Chicago Press

Wittgenstein L (1953/2009) Philosophical Investigations. Wiley-Blackwell

Wittgenstein L (1956/1983) Remarks on the Foundations of Mathematics. The MIT Press 